\title{
Defining Anastomotic Leak and the Clinical Relevance of Leaks
}

\author{
Clayton Tyler Ellis, MD, MSCR ${ }^{1}$ Justin A. Maykel, MD² \\ ${ }^{1}$ Division of Colorectal Surgery, Hiram C. Polk, Jr., MD, \\ Department of Surgery, University of Louisville, Louisville, Kentucky \\ 2 Division of Colorectal Surgery, Department of Surgery, University of \\ Massachusetts, Worcester, Massachusetts \\ Address for correspondence Clayton Tyler Ellis, MD, MSCR, Section of \\ Colorectal Surgery, Hiram C. Polk, Jr., MD, Department of Surgery, \\ University of Louisville, 550 South Jackson Street, Louisville, KY 40202 \\ (e-mail: clayton.ellis@louisville.edu).
}

Clin Colon Rectal Surg 2021;34:359-365.

\begin{abstract}
Surgeons universally dread gastrointestinal anastomotic leaks, yet the precise definition is not widely agreed on despite international consensus guidelines. Likewise, leaks are not uniformly reported which makes comparisons across studies flawed. Leak rates range from 1 to $3 \%$ for ileocolonic, 0.5 to $18 \%$ for colorectal, and 5 to $19 \%$ for coloanal anastomoses. The sequelae of an anastomotic leak vary but generally correlate with the need for a change in clinical management, from minimal changes to the need for reoperation. Short- and long-term outcomes can be life-altering or life-threatening.

Keywords

- definition

- colorectal

- anastomosis

- leak

- relevance Temporary or permanent stomas may be necessary and low pelvic anastomotic leaks may affect bowel function. For cancer patients, leaks can delay treatment and negatively affect oncologic outcomes. In Crohn's patients, leaks are associated with higher recurrence rates. In essence, the lack of agreement on the definition of an anastomotic leak inhibits meaningful understand of its epidemiology, prevention, and treatment.
\end{abstract}

\section{Definition of Large Bowel Anastomotic Leak}

\section{Definition}

The precise definition of a lower gastrointestinal (GI) anastomotic leak remains nebulous and ill defined. In a review of 97 studies from 1993 to 1999, the definition of a lower GI anastomotic leak was described 29 different ways. ${ }^{1}$ The lack of a uniform definition makes the true incidence unknown and comparisons between studies flawed resulting in up to $25 \%$ of patients who will be diagnosed with an anastomotic leak. ${ }^{2-4}$ Following a survey of the members of the American Society of Colon and Rectal Surgeons, a persistent lack of consensus among colorectal surgeons on the definition of an anastomotic leak despite international guidelines published a decade ago. ${ }^{5}$

In the modern era, the United Kingdom Surgical Infection Study Group was the first to propose standardized definitions "to allow meaningful comparisons to be made." ${ }^{6}$ In 1991, they defined an anastomotic leak as a "leak of luminal contents from a surgical joint between two hollow viscera," and a subclinical leak as "the escape of luminal contents from the site of the anastomosis into an adjacent localized area, detected by imaging, in the absence of clinical symptoms."

In 2010, the International Study Group of Rectal Cancer (ISREC) proposed a definition and grading system for colorectal anastomotic leaks. ${ }^{2}$ The ISREC defined a leak as "a defect of the intestinal wall at the anastomotic site (including suture and staple lines of neorectal reservoirs) leading to a communication between the intra- and extraluminal compartments." ${ }^{2}$ This definition was directed at leakage after an anterior rectal resection which may not be generalizable other GI anastomoses. ${ }^{7}$ In addition, the authors did not propose reliable methods of identifying such a communication in the postoperative period. However, this grading system remains one of the only standardized definitions for anastomotic leak. The ISREC delineated leaks by grades A to $C$ based on their clinical management ( - Table 1 ) which have been validated. ${ }^{8}$ There is significant difference in morbidity, length of stay, cost, and mortality between grade B
Issue Theme Anastomotic Leaks in Colorectal Surgery; Guest Editor: Anuradha R. Bhama, MD, FACS, FASCRS (c) 2021. Thieme. All rights reserved. Thieme Medical Publishers, Inc., 333 Seventh Avenue, 18th Floor, New York, NY 10001, USA 
Table 1 The International Study Group of Rectal Cancer (ISREC) anastomotic leak definition

\begin{tabular}{|l|l|}
\hline Grade A & Results in no change in management \\
\hline Grade B & $\begin{array}{l}\text { Requires active therapeutic intervention } \\
\text { short of a laparotomy }\end{array}$ \\
\hline Grade C & Requires relaparotomy \\
\hline
\end{tabular}

and $\mathrm{C}$ leaks. ${ }^{7,8}$ For these reasons, some have proposed that grades $B$ and $C$ to be separate entities due do the magnitude of difference between their management and outcomes. ${ }^{7}$

Further confusion occurs through the creation of additional nomenclature and categories of leaks. Some authors describe a "symptomatic leak," that is, grades B and C, as a clinical leak and an "asymptomatic leak," that is, grade A, as a subclinical leak. $^{6,9}$ In 2012, Adams and Papagrigoriadis surveyed colorectal surgeons in the United Kingdom on a working definition of anastomotic leaks. The authors found a good level of consensus defining a leak as "extravasation of contrast with an enema" and "fecal matter seen in the drains or from the wound regardless of management," 94.2 and $91.8 \%$, respectively. ${ }^{10}$ Yet, there was sharp disagreement with "radiological collections treated with antibiotics" or "... requiring percutaneous drainage." Half of the respondents did not consider collections requiring drainage or treated with antibiotics indicative of an anastomotic leak. ${ }^{10}$ Of the other half of respondents who agreed drainage constituted a leak, $89 \%$ felt similarly about collections treated with antibiotics. In relation to the ISREC definitions, there was good consensus for the working definition of grades $\mathrm{A}$ and $\mathrm{C}$ but disagreement for grade-B anastomotic leaks. Another study surveyed Dutch and Chinese surgeons on the definition of anastomotic leaks. Similar to British surgeons, there was a lack of consensus, except for computer tomography (CT) evidence of extravasation of rectal contrast. $^{11}$

The Delphi method survey of eight colorectal experts advocated for further refinement of the anastomotic leak. Using 15 clinical and radiological scenarios of leaks, only $80 \%$ of clinical and $30 \%$ of radiological scenarios reached consensus. ${ }^{5}$ For one particular controversial radiological scenario, when "air bubbles around the anastomosis" are visualized without other sequelae, there was consensus among experts that this scenario was indicative of an anastomotic leak. No agreement, however, was found when a CT scan with oral, intravenous, and rectal contrast demonstrated a fluid collection near the anastomosis without extravasation of contrast despite treatment with antibiotics and percutaneous drainage regardless of time frame out to 35 days. ${ }^{5}$ This further demonstrated the controversial nature of the definition of anastomotic leak.

\section{Categorization}

Anastomotic leaks present and are categorized in various ways as follows: (1) simple fistulas versus large sinuses; (2) intraperitoneal versus extraperitoneal; (3) sepsis-producing versus asymptomatic; or (4) early versus late. The identification of an anastomotic leak depends on clinical suspicion and subsequent workup. Anastomotic leaks located within the peritoneal cavity more often present with diffuse contamination, peritonitis, and sepsis. ${ }^{12}$ Extraperitoneal leaks may present in a less obvious fashion as a fistula, rectal drainage, pain, or urinary symptoms. ${ }^{13,14}$ Asymptomatic leaks are usually identified during an evaluation prior to diverting ileostomy takedown, for example, endoscopy, CT scan with or without contrast (-Fig. 1), or a lower GI series with contrast enema (-Fig. 2). ${ }^{2}$ In diverted patients, the true incidence of leaks is impacted by the spontaneously healing of unidentified, asymptomatic leaks. ${ }^{13,15}$ In a randomized, multicenter trial, patients with a diverting ostomy compared with those with no diversion were less likely to present with peritonitis and sepsis or require a laparotomy (10 vs. $28 \%$, respectively, $p<0.001 ; 8.6$ vs $25.4 \%, p<0.001){ }^{16}$ Although asymptomatic leaks were excluded, these data highlight a clear benefit in the sequelae of symptomatic leaks with proximal diversion. ${ }^{16}$ Two other randomized clinical trials have shown similar results with and without a colonic J-pouch. ${ }^{17,18}$

While proximal diversion offers protection against the clinical consequence of anastomotic leak, it is not without risks. Loop ileostomy closure has a reported complication rate of 11 to $18 \%$, including anastomotic leaks, wound complications, dehydration, and hospital readmission. ${ }^{19-23}$
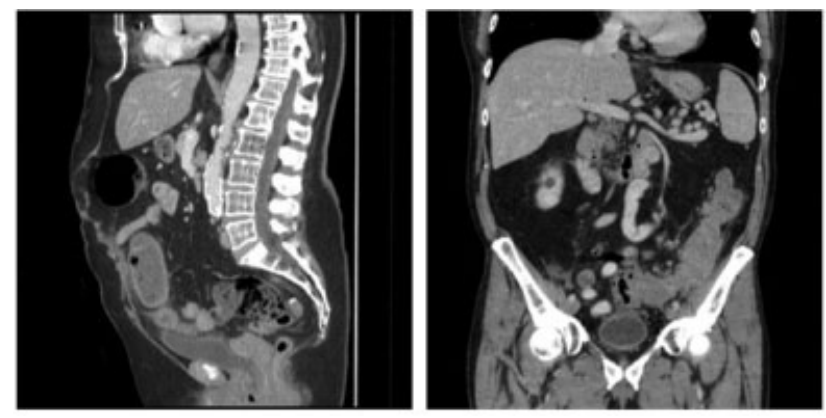

Fig. 1 Sagittal and coronal views of a colorectal anastomotic leak with extraluminal fluid and gas.

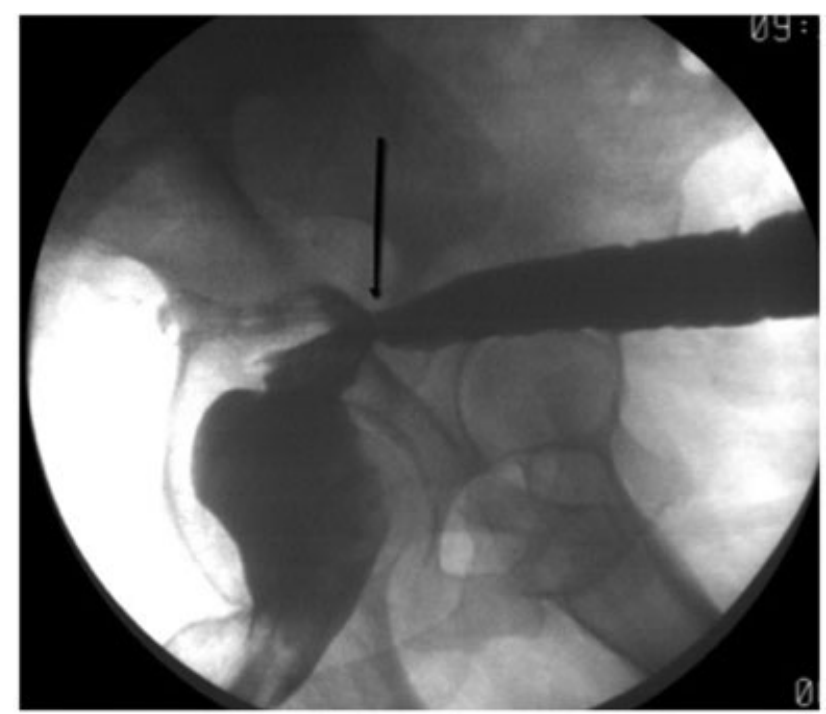

Fig. 2 Rectal contrast enema with posterior colorectal anastomotic leak (arrow) after low anterior resection. 
Li et al reported $13 \%$ readmission rate after diverting loop ileostomy creation with common reasons including organ space infections, ileus, and dehydration. ${ }^{22}$ Other studies have reported readmission rates after ileostomy creation up to $30 \%{ }^{20,21}$ Using a state surgical quality registry that included 1,737 patients undergoing a diverting loop ileostomy takedown, 11 and $7.4 \%$ of the cohort had a readmission and reoperation, respectively. ${ }^{23}$

Given the complications associated with not only the presence of ileostomy but also its subsequent reversal, some surgeons advocate for selective diversion. In a retrospective review in nonradiated low anterior resection (LAR) anastomoses, there was a 4 and $3.8 \%$ clinical leak rate in the diverted and nondiverted patients. ${ }^{24}$ These authors advocate for selective diversion in patients who can least withstand the sequela of a leak, that is, frail, elderly, or those with multiple comorbidities. ${ }^{24}$ In a recent administrative claimbased review, Chapman et al reported similar rates of anastomotic leaks after sphincter-sparing proctectomy with or without a diverting loop ileostomy, 4.5 versus $4.3 \%$, respectively. ${ }^{25}$ The diverted patients had higher rates of interventions, readmissions, and costs. ${ }^{25}$ While this study is thought provoking, administrative claims that data do not provide the granularity for appropriate comparison as these data are collected for billing purposes and have a reported sensitivity of $29 \%$ and positive predictive value of $13 \%$ of detecting anastomotic leaks. ${ }^{26}$

In summary of available studies, there are lower rates of clinically significant anastomotic leaks with proximal diversion compared with no diversion, and nonoperative management of leaks is more likely to be successful in diverted patients. However, the morbidity of a temporary stoma is not trivial and must be considered. Accordingly, selective diversion has been advocated, yet high-quality studies to support this practice are lacking.

\section{The Epidemiology of Anastomotic Leak}

The anatomic site of the anastomosis remains the most consistent and significant risk factor for anastomotic leak. ${ }^{27}$ The further distal an anastomosis is created, the higher the risk of leak. An ileocolic anastomosis has a leak rate of 1 to $4 \%$ compared with a 0.5 to $18 \%$ colorectal or a 5 to $19 \%$ leak rate in coloanal anastomoses. ${ }^{28}$ In rectal anastomoses, a significant difference can be seen with decreasing distance from the anal verge, ${ }^{27}$ with the highest risk of anastomotic leak at and below $5 \mathrm{~cm}$ from the anal verge. ${ }^{4,29,30}$ However, high-volume surgeons have reported leaks rates as low as $1.4 \%$ for all types of lower GI anastomoses. ${ }^{31}$

There are several proposed reasons for the difference in leak rates between proximal and distal colonic anastomotic locations. First, routine radiologic testing of anastomosis has been shown to detect 2.4 times more anastomotic leaks than clinical symptoms alone, and more radiological studies are performed to evaluate distal anastomoses. ${ }^{4,32}$ Second, the distal colon has an increased amount of intraluminal bacteria, compromised vascularity, and potentially increased intraluminal pressure compared with the proximal co- lon. ${ }^{33,34}$ In a prospective multicenter French study, Veyrie et al reported a significantly lower anastomotic leak rates for right-sided compared with left-sided colectomies for cancer, ( 1.35 vs. $5.20 \%, p<0.0001)$, with all patients receiving mechanical bowel preparation with parenteral preoperative antibiotic prophylaxis. ${ }^{34}$

\section{Ileocolic Anastomotic Leak}

As previously mentioned, ileocolic anastomoses are considered to have the lowest incidence of leaks, ranging from 1 to $3 \%, 434,35$ yet when leaks occur, peritonitis and sepsis are more common compared with extraperitoneal leaks. ${ }^{12}$

Patients with Crohn's disease (CD) are at a higher risk for an anastomotic leak ${ }^{36}$ which can have significant impact on disease recurrence. ${ }^{37}$ On retrospective review of a national registry, leak rates ranged from 1.6 to $14.3 \%$ by the number of risk factors for ileocolectomy for $\mathrm{CD}^{38}$ Emergent surgery, current smoking status, higher wound classifications, weight loss, and steroid use were strongly associated with anastomotic leaks. ${ }^{38}$ In one recent study, there was a $7.4 \%$ leak rate in $\mathrm{CD}$ patients with ileocolonic anastomoses which were unassociated with medications. ${ }^{39}$ However, steroid use is generally associated with this increased risk of leaks, while the role of biologic and immunomodulation medications remain debatable. ${ }^{40,41} \mathrm{~A}$ recent meta-analysis investigated the risk of leaks with biological medications for $\mathrm{CD}$ and did not find a significant association, however, the authors performed this meta-analysis without a clear and standardized definition of an anastomotic leak. ${ }^{42}$

\section{Colorectal Anastomotic Leak}

Extraperitoneal anastomoses and those under 5 to $8 \mathrm{~cm}$ from the anal verge are at a higher risk of a leak, 5 to $19 \%$, and proximal diversion is generally recommended. ${ }^{4,33,43}$ Diversion has been suggested to decrease the rate of leaks ${ }^{17,38}$ and significantly improve the morbidity associated with a leak. ${ }^{17}$ In a randomized, multicenter trial, Matthiessen et al compared the symptomatic leak rate for LARs for rectal cancer among diverted versus nondiverted patients. The diverted group had a significantly lower rate of symptomatic anastomotic leaks compared with the nondiverted group. The patients in the diverted group were $15 \%$ less likely to present with sepsis or require a laparotomy for management. ${ }^{16}$ Historically, diversion has not been considered to impact leak rates. ${ }^{44}$ In a large cohort from a single high-volume center, Nisar et al showed no statistical difference in diverted versus nondiverted patients. ${ }^{44}$ In this study, although not compared head-to-head, there was a clinical difference in anastomotic leaks between patients receiving neoadjuvant radiation who were diverted versus nondiverted, that is, 7.5 versus $11.6 \%$, respectively. ${ }^{44}$

Briefly, technical considerations that impact anastomotic leak rates include creation of tension-free and nonischemic anastomoses. Splenic flexure mobilization to relieve tension is associated with decrease leak rates for left-sided anastomoses. ${ }^{45}$ Every rectosigmoid and rectal anastomosis should be tested for a leak during the initial operation. ${ }^{46}$ In a singlecenter review, anastomotic leaks managed with suture 
repair alone $(n=41)$ compared with takedown with repeated anastomosis $(n=14)$ or proximal diversion $(n=10)$ had a 12.2 versus $0 \%$ postoperative clinical leak rate. ${ }^{46}$ The authors therefore advocate for an aggressive approach to redo or divert anastomoses that have air extravasation on insufflation testing.

\section{Coloanal Anastomotic Leak}

Coloanal anastomoses have the highest reported leak rate. LARs for distal tumors may be performed with a stapled coloanal anastomosis or a hand-sewn coloanal anastomosis with or without intersphincteric dissection. At experienced centers, a coloanal anastomosis after neoadjuvant chemoradiation (nCRT) has been shown to be oncologically safe with a low leak rate. ${ }^{47}$

The variability in reporting, that is, distance from anal verge to tumor versus distance to anastomosis, complicates comparison of leaks across studies. ${ }^{29}$ One series of 329 rectal cancer patients who underwent an ultra-LAR, that is, an anastomosis below the levator ani muscle, reported a leak rate of $5.5 \%{ }^{30}$ The majority of studies, however, reports significantly higher leak rates, albeit with smaller samples, ranging from $15^{48}$ to $24 \%{ }^{27,49}$ Significant risk factors include nCRT and male gender, which is presumed to be due to the technical challenges of working in a narrow pelvis. $29,48,49$ Additionally, documented leaks that healed are at risk for recurrent leaks. Kitaguchi et al reported recurrent anastomotic leaks after proximal diverting stoma closure occur 5 and $25 \%$ after low anterior and coloanal anastomoses, respectively. ${ }^{50}$

\section{Ileal-Pouch Anal Anastomosis Leak}

A leak from an unprotected ileal-pouch anal anastomosis (IPAA) may have devastating complications, including loss of the pouch. The true incidence of leaks after an IPAA is unknown. Most publications are retrospective reviews from high-volume single centers and leaks are generally included under the subheading pelvic sepsis. Reported leak and fistula rates after IPAA are 3.2 to 19 and 1 to $7 \%$, respectively. ${ }^{40,48,51-53}$ The tip of a J-pouch has a reported leak rate of $0.5 \%{ }^{54}$ Anastomotic complications are significantly higher for patients with ulcerative colitis compared with familial adenomatous polyposis, especially in the setting of preoperative steroid use. ${ }^{51,55}$ Late presentations of leaks and fistulas after an IPAA for ulcerative colitis should prompt a workup for CD.

\section{The Impact of Anastomotic Leak}

\section{Short-Term Outcomes}

Lack of bowel function beyond the sixth postoperative day is highly predictive of an anastomotic leak, but the presence of bowel function alone is a poor negative predictor. ${ }^{56,57}$ Sometimes patients may not display any one sign or symptom, but simply fail to progress, that is, follow the standard postoperative course. These patients warrant an evaluated for an anastomotic leak. ${ }^{12}$ On average, patients with an anastomotic leak compared with those without a leak spend almost a week longer in the hospital. ${ }^{57,58}$ The median time to diagnosis has a reported range between 12 and 17 days from the time of surgery, at which point patients may have been discharged from the hospital. ${ }^{59-61}$ A single-center review reported $32 \%$ of leaks are diagnosed over 30 days from the initial operation. ${ }^{14}$ Mortality after a leak can be six-fold higher than patients without a leak, $12 \%$ compared with $1.6 \%{ }^{62}$ In one study, patients with grade-B leaks had a mortality of $2.5 \%$ and those with grade $C, 5.8 \%, p=0.12 .7$

\section{Long-Term Outcomes}

Anastomotic leaks can have a significant impact on a patient's bowel function and quality of life (QOL). Even without complications, colorectal and coloanal anastomoses have a measurable effect on function and QOL. ${ }^{63,64}$ An anastomotic leak can lead to pelvic fibrosis which contributes to poor anorectal function by reduction compliance and capacity of the neorectum. ${ }^{65-67}$ The resulting scar may impact pelvic floor and sphincter function, even if the anastomotic leak completely heals. ${ }^{13}$ Ashburn et al compared patients with and without anastomotic leaks after restorative proctectomy. ${ }^{67}$ Individuals with an anastomotic leak were more likely to have frequent day- and night-time bowel movements and worse control of solid stool compared with patients without a leak 1-year postproctectomy. ${ }^{67} \mathrm{QOL}$ scores, also, were significantly lower for individuals with a leak compared with those without a leak at 1 year. ${ }^{67}$ Other studies have reported similar results for symptomatic leaks. ${ }^{68-70}$ Inflammatory bowel disease (IBD) patients with an anastomotic leak after an IPAA have a reported pouch failure of $4.5 \%{ }^{71}$

Hain et al reported higher LAR syndrome (LARS) scores for symptomatic leaks but no difference on LARS scores for asymptomatic leaks. ${ }^{70}$ Recent studies evaluating colon Jpouch compared with side-to-end or end-to-end colorectal anastomosis report similar functional outcomes. ${ }^{72,73} \mathrm{Al}-$ though these studies were underpowered to evaluate the impact of an anastomotic leak on function, there is no evidence to support a superior colorectal anastomotic technique. $^{72,73}$ Permanent stoma rates after lower GI anastomotic leaks have been reported up to $50 \%$. $^{16,59,74}$

\section{Oncologic Outcomes}

Studies investigating the association between anastomotic leaks and oncologic outcomes after colorectal cancer surgery are conflicting. A meta-analysis including 21 studies and 21,092 patients concluded that anastomotic leaks had a negative prognostic impact on local recurrence but not distant recurrence. ${ }^{75,76}$ For stage-III colon cancer patients, another study found leaks were associated with increased rates of distant recurrence and long-term mortality. ${ }^{77}$ Krarup et al reported the leak group had significant delays or cancelation of adjuvant chemotherapy, which is a strong confounding factor of oncologic outcomes but also likely the reason for this discrepancy. ${ }^{77}$ A recent single-center review of 698 rectal cancer patients who underwent nCRT followed by a total mesorectal excision reported no association between anastomotic leaks and oncologic outcome. ${ }^{78}$ In more 
recent years, total neoadjuvant therapy (TNT) for rectal cancer has been shown to increase treatment adherence with decreased toxicities. ${ }^{79}$ TNT may potentially improve oncologic outcomes in patients with anastomotic leaks by avoiding delays in oncologic treatment. ${ }^{80}$

\section{Costs Associated with Anastomotic Leak}

Anastomotic leaks double to triple the costs of medical care. ${ }^{81,82}$ The reported average incremental costs associated with a leak for each hospitalization is $\$ 24,129 .^{58}$ There are few studies reporting the costs of leaks in dollars, however, the costs can be extrapolated from additional days in the hospital and ICU, as well as the increased number of treatment procedures. ${ }^{7}$ Additionally, complications decrease the profit margin of procedures and in some cases, may even be net negative. ${ }^{83}$ To date, the costs associated with patients' loss of productivity due to anastomotic leaks have not been evaluated.

\section{Conclusion}

An anastomotic leak can result in a wide range of presentations, from an asymptomatic, clinical insignificant radiologic finding to a septic insult, causing a rapid decline with multiorgan failure and death. Variability of reported definitions in research investigations, specifically the underreporting of grade-A leaks, make comparisons and conclusions difficult to interpret across studies. The goal of this review was to highlight the need for universal standardization and reporting of anastomotic leaks and to outline the short- and long-term outcomes associated with anastomotic leaks.

\section{Disclaimers}

This manuscript is original and neither published, accepted, or submitted for publication elsewhere.

\section{Authors' Contributions}

All authors have made (1) substantial contributions to conception and design, or acquisition of data, or analysis and interpretation of data; (2) drafting the article or revising it critically for import intellectual content; and (3) final approval of the version to be published.

\section{Source of Funding}

No external funding was provided for this work.

\section{Conflict of Interest}

The authors have no relevant conflicts of interest to report.

\section{References}

1 Bruce J, Krukowski ZH, Al-Khairy G, Russell EM, Park KG. Systematic review of the definition and measurement of anastomotic leak after gastrointestinal surgery. Br J Surg 2001;88(09):1157-1168

2 Rahbari NN, Weitz J, Hohenberger W, et al. Definition and grading of anastomotic leakage following anterior resection of the rectum: a proposal by the International Study Group of Rectal Cancer. Surgery 2010;147(03):339-351
3 Eckmann C, Kujath P, Schiedeck THK, Shekarriz H, Bruch H-P. Anastomotic leakage following low anterior resection: results of a standardized diagnostic and therapeutic approach. Int J Colorectal Dis 2004;19(02):128-133

4 McDermott FD, Heeney A, Kelly ME, Steele RJ, Carlson GL, Winter DC. Systematic review of preoperative, intraoperative and postoperative risk factors for colorectal anastomotic leaks. Br J Surg 2015;102(05):462-479

5 Daniel VT, Alavi K, Davids JS, et al. The utility of the delphi method in defining anastomotic leak following colorectal surgery. Am J Surg 2020;219(01):75-79

6 Peel AL, Taylor EWSurgical Infection Study Group. Proposed definitions for the audit of postoperative infection: a discussion paper. Ann R Coll Surg Engl 1991;73(06):385-388

7 Frouws MA, Snijders HS, Malm SH, et al. Clinical relevance of a grading system for anastomotic leakage after low anterior resection: analysis from a national cohort database. Dis Colon Rectum 2017;60(07):706-713

8 Kulu Y, Ulrich A, Bruckner T, et al; International Study Group of Rectal Cancer. Validation of the International Study Group of Rectal Cancer definition and severity grading of anastomotic leakage. Surgery 2013;153(06):753-761

9 Ripollés-Melchor J, Ramírez-Rodríguez JM, Casans-Francés R, et al; POWER Study Investigators Group for the Spanish Perioperative Audit and Research Network (REDGERM) Association between use of enhanced recovery after surgery protocol and postoperative complications in colorectal surgery: the postoperative outcomes within enhanced recovery after surgery protocol (POWER) Study. JAMA Surg 2019;154(08):725-736

10 Adams K, Papagrigoriadis S. Little consensus in either definition or diagnosis of a lower gastro-intestinal anastomotic leak amongst colorectal surgeons. Int J Colorectal Dis 2013;28(07): 967-971

11 van Rooijen SJ, Jongen AC, Wu Z-Q et al. Definition of colorectal anastomotic leakage: a consensus survey among Dutch and Chinese colorectal surgeons. World J Gastroenterol 2017;23 (33):6172-6180

12 Smallwood N, Mutch MG, Fleshman JW. The failed anastomosis. In: Steele SR, Maykel JA, Champagne BJ, Orangio GR, eds. Complexities in Colorectal Surgery. New York, NY: Springer-Verlag; 2014:277-304

13 Lim M, Akhtar S, Sasapu K, et al. Clinical and subclinical leaks after low colorectal anastomosis: a clinical and radiologic study. Dis Colon Rectum 2006;49(10):1611-1619

14 Tan WP, Hong EY, Phillips B, Isenberg GA, Goldstein SD. Anastomotic leaks after colorectal anastomosis occurring more than 30 days postoperatively: a single-institution evaluation. Am Surg 2014;80(09):868-872

15 Hedrick TL, Sawyer RG, Foley EF, Friel CM. Anastomotic leak and the loop ileostomy: friend or foe? Dis Colon Rectum 2006;49(08): 1167-1176

16 Matthiessen P, Hallböök O, Rutegård J, Simert G, Sjödahl R. Defunctioning stoma reduces symptomatic anastomotic leakage after low anterior resection of the rectum for cancer: a randomized multicenter trial. Ann Surg 2007;246(02): 207-214

17 Mrak K, Uranitsch S, Pedross F, et al. Diverting ileostomy versus no diversion after low anterior resection for rectal cancer: A prospective, randomized, multicenter trial. Surgery 2016;159(04): 1129-1139

18 Chude GG, Rayate NV, Patris V, et al. Defunctioning loop ileostomy with low anterior resection for distal rectal cancer: should we make an ileostomy as a routine procedure? A prospective randomized study. Hepatogastroenterology 2008;55(86-87): 1562-1567

19 Wong K-S, Remzi FH, Gorgun E, et al. Loop ileostomy closure after restorative proctocolectomy: outcome in 1,504 patients. Dis Colon Rectum 2005;48(02):243-250 
20 Justiniano CF, Temple LK, Swanger AA, et al. Readmissions with dehydration after ileostomy creation: rethinking risk factors. Dis Colon Rectum 2018;61(11):1297-1305

21 Chen SY, Stem M, Cerullo M, et al. Predicting the risk of readmission from dehydration after ileostomy formation: the dehydration readmission after ileostomy prediction score. Dis Colon Rectum 2018;61(12):1410-1417

22 Li W, Stocchi L, Cherla D, et al. Factors associated with hospital readmission following diverting ileostomy creation. Tech Coloproctol 2017;21(08):641-648

23 Bhama AR, Batool F, Collins SD, Ferraro J, Cleary RK. Risk factors for postoperative complications following diverting loop ileostomy takedown. J Gastrointest Surg 2017;21(12):2048-2055

24 Wong NY, Eu KW. A defunctioning ileostomy does not prevent clinical anastomotic leak after a low anterior resection: a prospective, comparative study. Dis Colon Rectum 2005;48(11): 2076-2079

25 Chapman WC Jr., Subramanian M, Jayarajan S, et al. First, do no harm: rethinking routine diversion in sphincter-preserving rectal cancer resection. J Am Coll Surg 2019;228(04):547-556.e8

26 Reinke CE, Showalter S, Mahmoud NN, Kelz RR. Comparison of anastomotic leak rate after colorectal surgery using different databases. Dis Colon Rectum 2013;56(05):638-644

27 Boccola MA, Buettner PG, Rozen WM, et al. Risk factors and outcomes for anastomotic leakage in colorectal surgery: a single-institution analysis of 1576 patients. World J Surg 2011;35 (01):186-195

28 McKenna NP, Bews KA, Cima RR, Crowson CS, Habermann EB. Development of a risk score to predict anastomotic leak after leftsided colectomy: which patients warrant diversion? J Gastrointest Surg 2020;24(01):132-143

29 Bertelsen CA, Andreasen AH, Jørgensen T, Harling HDanish Colorectal Cancer Group. Anastomotic leakage after anterior resection for rectal cancer: risk factors. Colorectal Dis 2010;12(01):37-43

30 Jung SH, Yu CS, Choi PW, et al. Risk factors and oncologic impact of anastomotic leakage after rectal cancer surgery. Dis Colon Rectum 2008;51(06):902-908

31 Delaney CP, Brady K, Woconish D, Parmar SP, Champagne BJ. Towards optimizing perioperative colorectal care: outcomes for 1,000 consecutive laparoscopic colon procedures using enhanced recovery pathways. Am J Surg 2012;203(03):353-355, discussion 355-356

32 Platell C, Barwood N, Dorfmann G, Makin G. The incidence of anastomotic leaks in patients undergoing colorectal surgery. Colorectal Dis 2007;9(01):71-79

33 Benoist S, Panis Y, Alves A, Valleur P. Impact of obesity on surgical outcomes after colorectal resection. Am J Surg 2000;179(04): 275-281

34 Veyrie N, Ata T, Muscari F, et al; French Associations for Surgical Research. Anastomotic leakage after elective right versus left colectomy for cancer: prevalence and independent risk factors. J Am Coll Surg 2007;205(06):785-79

35 de Buck van Overstraeten A, Eshuis EJ, Vermeire S, et al. Short- and medium-term outcomes following primary ileocaecal resection for Crohn's disease in two specialist centres. Br J Surg 2017;104 (12):1713-1722

36 Lipska MA, Bissett IP, Parry BR, Merrie AEH. Anastomotic leakage after lower gastrointestinal anastomosis: men are at a higher risk. ANZ J Surg 2006;76(07):579-585

37 Iesalnieks I, Kilger A, Glass H, et al. Intraabdominal septic complications following bowel resection for Crohn's disease: detrimental influence on long-term outcome. Int J Colorectal Dis 2008; 23(12):1167-1174

38 Neary PM, Aiello AC, Stocchi L, et al. High-risk ileocolic anastomoses for Crohn's disease: when is diversion indicated? J Crohn's Colitis 2019;13(07):856-863

39 Gutiérrez A, Rivero M, Martín-Arranz MD, et al. Perioperative management and early complications after intestinal resection with ileocolonic anastomosis in Crohn's disease: analysis from the PRACTICROHN study. Gastroenterol Rep (Oxf) 2019;7(03): 168-175

40 Jouvin I, Lefevre JH, Creavin B, et al; Saint-Antoine IBD Network. Postoperative morbidity risks following ileocolic resection for Crohn's disease treated with anti-TNFalpha therapy: a retrospective study of 360 patients. Inflamm Bowel Dis 2018;24(02):422-432

41 Yamamoto T, Spinelli A, Suzuki Y, et al. Risk factors for complications after ileocolonic resection for Crohn's disease with a major focus on the impact of preoperative immunosuppressive and biologic therapy: A retrospective international multicentre study. United European Gastroenterol J 2016;4(06):784-793

42 Waterland P, Athanasiou T, Patel H. Post-operative abdominal complications in Crohn's disease in the biological era: Systematic review and meta-analysis. World J Gastrointest Surg 2016;8(03): 274-283

43 Vignali A, Fazio VW, Lavery IC, et al. Factors associated with the occurrence of leaks in stapled rectal anastomoses: a review of 1,014 patients. J Am Coll Surg 1997;185(02):105-113

44 Nisar PJ, Lavery IC, Kiran RP. Influence of neoadjuvant radiotherapy on anastomotic leak after restorative resection for rectal cancer. J Gastrointest Surg 2012;16(09):1750-1757

45 Karanjia ND, Corder AP, Bearn P, Heald RJ. Leakage from stapled low anastomosis after total mesorectal excision for carcinoma of the rectum. Br J Surg 1994;81(08):1224-1226

46 Ricciardi R, Roberts PL, Marcello PW, Hall JF, Read TE, Schoetz DJ Anastomotic leak testing after colorectal resection: what are the data? Arch Surg 2009;144(05):407-411, discussion 411-412

47 Weiser MR, Quah H-M, Shia J, et al. Sphincter preservation in low rectal cancer is facilitated by preoperative chemoradiation and intersphincteric dissection. Ann Surg 2009;249(02):236-242

48 Trencheva K, Morrissey KP, Wells M, et al. Identifying important predictors for anastomotic leak after colon and rectal resection: prospective study on 616 patients. Ann Surg 2013;257(01): 108-113

49 Matthiessen P, Hallböök O, Andersson M, Rutegård J, Sjödahl R. Risk factors for anastomotic leakage after anterior resection of the rectum. Colorectal Dis 2004;6(06):462-469

50 Kitaguchi D, Nishizawa Y, Sasaki T, Tsukada Y, Ikeda K, Ito M. Recurrence of rectal anastomotic leakage following stoma closure: assessment of risk factors. Colorectal Dis 2019;21(11):1304-1311

51 Francone TD, Champagne B. Considerations and complications in patients undergoing ileal pouch anal anastomosis. Surg Clin North Am 2013;93(01):107-143

52 Bach SP, Mortensen NJ. Ileal pouch surgery for ulcerative colitis. World J Gastroenterol 2007;13(24):3288-3300

53 Fazio VW, Kiran RP, Remzi FH, et al. Ileal pouch anal anastomosis: analysis of outcome and quality of life in 3707 patients. Ann Surg 2013;257(04):679-685

54 Kirat HT, Kiran RP, Oncel M, Shen B, Fazio VW, Remzi FH. Management of leak from the tip of the "J" in ileal pouch-anal anastomosis. Dis Colon Rectum 2011;54(04):454-459

55 Lovegrove RE, Tilney HS, Heriot AG, et al. A comparison of adverse events and functional outcomes after restorative proctocolectomy for familial adenomatous polyposis and ulcerative colitis. Dis Colon Rectum 2006;49(09):1293-1306

56 Bellows CF, Webber LS, Albo D, Awad S, Berger DH. Early predictors of anastomotic leaks after colectomy. Tech Coloproctol 2009; 13(01):41-47

57 Fouda E, El Nakeeb A, Magdy A, Hammad EA, Othman G, Farid M. Early detection of anastomotic leakage after elective low anterior resection. J Gastrointest Surg 2011;15(01):137-144

58 Hammond J, Lim S, Wan Y, Gao X, Patkar A. The burden of gastrointestinal anastomotic leaks: an evaluation of clinical and economic outcomes. J Gastrointest Surg 2014;18(06):1176-1185

59 Thornton M, Joshi H, Vimalachandran C, et al. Management and outcome of colorectal anastomotic leaks. Int J Colorectal Dis 2011; 26(03):313-320 
60 Lim S-B, Yu CS, Kim CW, Yoon YS, Park IJ, Kim JC. Late anastomotic leakage after low anterior resection in rectal cancer patients: clinical characteristics and predisposing factors. Colorectal Dis 2016;18(04):0135-0140

61 Hyman N, Manchester TL, Osler T, Burns B, Cataldo PA. Anastomotic leaks after intestinal anastomosis: it's later than you think. Ann Surg 2007;245(02):254-258

62 Alves A, Panis Y, Trancart D, Regimbeau J-M, Pocard M, Valleur P. Factors associated with clinically significant anastomotic leakage after large bowel resection: multivariate analysis of 707 patients. World J Surg 2002;26(04):499-502

63 Temple LK, Bacik J, Savatta SG, et al. The development of a validated instrument to evaluate bowel function after sphincter-preserving surgery for rectal cancer. Dis Colon Rectum 2005; 48(07):1353-1365

64 Gamagami R, Istvan G, Cabarrot P, Liagre A, Chiotasso P, Lazorthes F. Fecal continence following partial resection of the anal canal in distal rectal cancer: long-term results after coloanal anastomoses. Surgery 2000;127(03):291-295

65 Carmona JA, Ortiz H, Perez-Cabañas I. Alterations in anorectal function after anterior resection for cancer of the rectum. Int J Colorectal Dis 1991;6(02):108-110

66 Jorge JM, Wexner SD. Anorectal manometry: techniques and clinical applications. South Med J 1993;86(08):924-931

67 Ashburn JH, Stocchi L, Kiran RP, Dietz DW, Remzi FH. Consequences of anastomotic leak after restorative proctectomy for cancer: effect on long-term function and quality of life. Dis Colon Rectum 2013;56(03):275-280

68 Hallböök O, Sjödahl R. Anastomotic leakage and functional outcome after anterior resection of the rectum. Br J Surg 1996;83 (01):60-62

69 Nesbakken A, Nygaard K, Lunde OC. Outcome and late functional results after anastomotic leakage following mesorectal excision for rectal cancer. Br J Surg 2001;88(03):400-404

70 Hain E, Manceau G, Maggiori L, Mongin C, Prost À la Denise J, Panis Y. Bowel dysfunction after anastomotic leakage in laparoscopic sphincter-saving operative intervention for rectal cancer: a casematched study in 46 patients using the low anterior resection score. Surgery 2017;161(04):1028-1039

71 Breen EM, Schoetz DJ Jr., Marcello PW, et al. Functional results after perineal complications of ileal pouch-anal anastomosis. Dis Colon Rectum 1998;41(06):691-695

72 Parc Y, Ruppert R, Fuerst A, et al. Better function with a colonic JPouch or a side-to-end anastomosis?: a randomized controlled trial to compare the complications, functional outcome, and quality of life in patients with low rectal cancer after a Jpouch or a side-to-end anastomosis Ann Surg 2019;269(05): 815-826

73 Marti WR, Curti G, Wehrli H, et al; Swiss Group for Clinical Cancer Research (SAKK), Section Surgery. Clinical outcome after rectal replacement with side-to-end, colon-J-pouch, or straight colorectal anastomosis following total mesorectal excision: a Swiss prospective, randomized, multicenter trial (SAKK 40/04). Ann Surg 2019;269(05):827-835

74 Francone TD, Saleem A, Read TA, et al. Ultimate fate of the leaking intestinal anastomosis: does leak mean permanent stoma? J Gastrointest Surg 2010;14(06):987-992

75 Mirnezami A, Mirnezami R, Chandrakumaran K, Sasapu K, Sagar P, Finan P. Increased local recurrence and reduced survival from colorectal cancer following anastomotic leak: systematic review and meta-analysis. Ann Surg 2011;253(05):890-899

76 Branagan G, Finnis DWessex Colorectal Cancer Audit Working Group. Prognosis after anastomotic leakage in colorectal surgery. Dis Colon Rectum 2005;48(05):1021-1026

77 Krarup P-M, Nordholm-Carstensen A, Jorgensen LN, Harling H. Anastomotic leak increases distant recurrence and long-term mortality after curative resection for colonic cancer: a nationwide cohort study. Ann Surg 2014;259(05):930-938

78 Jang JH, Kim HC, Huh JW, et al. Anastomotic leak does not impact oncologic outcomes after preoperative chemoradiotherapy and resection for rectal cancer. Ann Surg 2019;269(04):678-685

79 Fernández-Martos C, Pericay C, Aparicio J, et al. Phase II, randomized study of concomitant chemoradiotherapy followed by surgery and adjuvant capecitabine plus oxaliplatin (CAPOX) compared with induction CAPOX followed by concomitant chemoradiotherapy and surgery in magnetic resonance imagingdefined, locally advanced rectal cancer: Grupo cancer de recto 3 study. J Clin Oncol 2010;28(05):859-865

80 Cercek A, Roxburgh CSD, Strombom P, et al. Adoption of total neoadjuvant therapy for locally advanced rectal cancer. JAMA Oncol 2018;4(06):e180071-e180071

81 Turrentine FE, Denlinger CE, Simpson VB, et al. Morbidity, mortality, cost, and survival estimates of gastrointestinal anastomotic leaks. J Am Coll Surg 2015;220(02):195-206

82 Vonlanthen R, Slankamenac K, Breitenstein S, et al. The impact of complications on costs of major surgical procedures: a cost analysis of 1200 patients. Ann Surg 2011;254(06):907-913

83 Healy MA, Mullard AJ, Campbell DA Jr., Dimick JB. Hospital and payer costs associated with surgical complications. JAMA Surg 2016;151(09):823-830 